\title{
KAJIAN DESAIN DASAR SALURAN IRIGASI BENDUNGAN "TIWUNGAJA" UNTUK PERLUASAN AREAL SAWAH BARU DI DESA SOBO I, KECAMATAN GOLEWA BARAT, KABUPATEN NGADA, NUSA TENGGARA TIMUR
}

\section{ASSESSMENT OF BASIC DESIGN OF “TIWUNGAJA" DAM IRRIGATION CHANNEL FOR NEW PADDY RICE AREA EXPLANATION IN SOBO I VILLAGE, GOLEWA BARAT DISTRICT, NGADA REGENCY, TIMUR NUSA TENGGARA}

\author{
Yohanes Nangameka \\ Program Studi Agribisnis, Fakultas Pertanian, Universitas Abdurachman Saleh Situbondo \\ Email: comodo.consultan@yahoo.co.id
}

\begin{abstract}
ABSTRAK
Dalam melaksanakan pembangunan pertanian, air menjadi salah satu unsur utama. Namun dewasa ini masalah utama dihadapi dalam pengelolaan sumber daya air adalah belum ditentukan potensi sumber daya air yang dapat dimanfaatkan. Saluran irigasi adalah bagian dari prasarana untuk memanfaatkan sumber daya air. Maka, dalam penelitiaan ini, akan mengkaji desain dasar saluran irigasi dari bendungan Tiwungaja, yang potensial untuk perluasan areal sawah baru di Desa Sobo I, Kacamatan Golewa Barat, Kabupaten Ngada. Sungai yang mengalir untuk penyediaan air bendungan Tiwungaja adalah sungai Aesesa hulu dengan debit 4.775 liter per detik, dan debit air total sungai yang mengalir di Kabupaten Ngada sebesar 17.583 liter per detik, yang masih dapat dikembangkan untuk proyek perluasan areal sawah seluas 210 ha. Metode yang digunakan di dalam penelitian ini adalah deskriptif analisis, untuk mengkaji desain dasar saluran irigasi bendungan "Tiwungaja" guna perluasan areal sawah baru. Bagaimana bentuk desain dasar irigasi akan diteliti didalam penelitian ini. Penelitian ini bertujuan untuk membuat desain dasar saluran irigasi bendungan Tiwungaja untuk perluasan areal sawah baru, dengan target yang ingin dicapai di dalam penelitian ini adalah: 1) Penentuan panjang jalan inspeksi saluran irigasi; 2) Penentuan perpanjangan saluran primer untuk perluasan sawah baru; 3) Penentuan perpanjangan saluran sekunder; 4) Untuk perluasan sawah baru; 5) Penentuan letak pintu air saluran sekunder untuk masing blok areal sawah. Penelitian ini menggunakan data primer, data sekunder dan teknik analisa data dengan menggunakan analisa SWOT.
\end{abstract}

Kata Kunci: Air, Saluran irigasi, Bendungan

\begin{abstract}
In carrying out agricultural development, water is one of the main elements. Nowadays the main problem in the management of water resources is that the potential of water resources that can be utilized has not been determined. Irrigation channels are part of the infrastructure to utilize water resources. So, in this study, we will examine the basic design of the irrigation canal from the Tiwungaja dam, which has the potential for expansion of new rice fields in Sobo I Village, West Golewa Golewa, Ngada Regency. The river that flows for the Tiwungaja water supply is the upstream Aesesa river with a flow rate of 4,775 liters per second, and the total river water flow in Ngada Regency is 17,583 liters per second, which can still be developed for a 210 ha rice field expansion project. The method used in this study is descriptive analysis, for the basic design of the
\end{abstract}


P-ISSN 2580 - 7781

E-ISSN 2615 - 3238

"Tiwungaja" dam irrigation channel for the expansion of new rice fields. How the basic design of irrigation will be investigated in this study. This study aims to make the basic design of the Tiwungaja dam irrigation channel for the expansion of new rice fields, with the targets to be achieved in this study are: 1) Determination of the length of the irrigation canal inspection road; 2) Determination of the extension of the primary channel for the expansion of new rice fields; 3) Determination of secondary channel extension; 4) For the expansion of new rice fields; 5) Determination of the location of the secondary channel sluice gate for each block of rice fields. This study uses primary data and secondary data and data analysis techniques using SWOT analysis.

Keywords: Water, Irrigation channel, Dam

\section{PENDAHULUAN}

Sumber daya air di Indonesia yang termasuk dalam kawasan tropika basah (Okdeman, 1977) dengan curah hujan rata-rata tinggi. Hujan rata-rata tahunan untuk seluruh kawasan Indonesia sebesar $2.600 \mathrm{~mm}$ dangan variasi antara 1.000 sampai $3.000 \mathrm{~mm}$. Dari curah hujan sebesar $2.600 \mathrm{~mm}$, sebesar $1.370 \mathrm{~mm}$ hilang melalui penguapan dan meresap menjadi air tanah dalam. Sementara sebesar $1.250 \mathrm{~mm}$ sisanya menjadi aliran, yang setara dengan $2.380 \mathrm{~km}^{3}$. Aliran air ini yang sangat potensial untuk proyek irigasi pertanian.

Menurut Russel (1973), air hanya akan mengalir di permukaan tanah apabila laju atau jumlah air hujan lebih besar dari kemampuan tanah untuk menginfiltrasikan air ke lapisan yang lebih dalam. Dalam hal ini setiap faktor yang dapat mengurangi permeabilitas tanah akan naik sesuai dengan naiknya jumlah air yang mengalir di permukaan.

Dalam rangka menyelamatkan sumber daya alam hutan, tanah dan sumber air Indonesia, pemerintah telah mengambil langkah-langkah yang diperlukan antara lain dengan dikeluarkannya Surat Keputusan bersama tiga menteri yaitu Menteri Dalam Negeri, Menteri Kehutanan dan Menteri Pekerjaan Umum Nomor : 19 Tahun 1984-No : 059/Kpts-II/ 1984-No : 124/Kpts/1984 tanggal 4 April 1984, Tentang Penanganan Konservasi Tanah dalam Rangka Pengamanan Daerah Aliran Sungai Prioritas. Isi pokok surat keputusan bersama tersebut adalah :

Wilayah Kerja: Menetapkan wilayah kerja konservasi tanah dikonsentrasikan pada 22 (dua puluh dua) Daerah Aliran Sungai (DAS) Super Prioritas. Pada tahun 2000 DAS kritis telah bertambah menjadi 58 DAS kritis prioritas. Untuk Propinsi 
P-ISSN 2580 - 7781

E-ISSN $2615-3238$

NTT terdiri dari 4 DAS yaitu DAS Benain, DAS Noelmina, DAS Kambaheru dan DAS Aisesa.

Dasar Penetapan DAS Prioritas: Penetapan DAS Prioritas berdasarkan kriteria sebagai berikut : DAS yang hidro orologisnya kritis, ditandai oleh rendahnya prosentase penutupan lahan, tingginya laju erosi tahunan, dan besarnya nisbah debit sungai maksimum (musim hujan) dan debit minimum (musim kemarau) serta kandungan lumpur (sedimen load) yang berlebihan.

Urgensi perlindungan investasi yang telah, sedang, atau akan dibangun bangunan vital dengan investasi besar di daerah hilirnya, antara lain waduk, bendung dan bangunan pengairan lainnya.

Manajemen pengelolaan air yang mengalir dalam saluran atau sungai dapat berasal dari aliran permukaan atau dari air tanah yang merembes di dasar sungai. Kontribusi air tanah pada aliran sungai disebut aliran dasar (baseflow), sementara total aliran disebut debit (run off). Air yang tersimpan di waduk, danau dan sungai disebut air permukaan (surface water). Dalam kaitan dengan konservasi air, dua komponen dalam siklus hidrologi yang terpenting yaitu air permukaan dan air tanah, oleh karena kedua komponen inilah yang merupakan sumber utama air yang dimanfaatkan manusia untuk memenuhi kebutuhan hidupnya.

Kompenen air permukaan meliputi air sungai (rivers), saluran (streams), sumber (springs), danau, dan waduk. Jumlah air permukaan diperkirakan hanya 0,35 juta $\mathrm{km}^{3}$ atau hanya sekitar satu persen dari air tawar yang ada di bumi. Air permukaan berasal dari aliran langsung air hujan, lelehan salju, dan aliran yang berasal dari air tanah.

Pada saat mulai hujan semua air akan terinfiltrasi, tetapi setelah laju infiltrasi turun dibawah intensitas hujan, sisa air hujan akan tetap di atas permukaan tanah. Jika aliran permukaan akan terjadi hanya jika intensitas hujan lebih tinggi dari laju infiltrasi, dan kapasitas depresi sudah terisi. Setelah laju infitrasi terpenuhi, air mulai mengisi cekungan-cekungan di permukaan tanah. Begitu cekungan-cekungan terisi, aliran permukaan mulai terjadi.

Besar kecilnya aliran dipengaruhi oleh banyak faktor yang dapat dikelompokan menjadi dua, yaitu faktor-faktor yang berkaitan dengan iklim 
P-ISSN 2580 - 7781

E-ISSN $2615-3238$

(khusunya curah hujan), dan faktor-faktor yang berkaitan dengan karakteristik Daerah Aliran Sungai (DAS). Pengendalian air permukaan: dalam siklus hidrologi, sebagian besar air hujan yang sampai ke tanah mengalir terbuang ke laut berupa aliran permukaan. Sisanya kembali ke udara, baik melalui tanah, badan air maupun transpirasi tumbuhan. Hasil penelitian mengarahkan pada kita bahwa kemungkinan terbaik untuk konservasi air adalah mengendalikan bagian air hujan yang mengalir di atas permukaan tanah. Pengendalian air permukaan dilakukan dengan cara memperpanjang waktu air tertahan di permukaan tanah dan meningkatkan jumlah air yang masuk ke dalam tanah. Penelitian aliran permukaan pada petak percobaan dengan tanaman lahan kering untuk berbagai jenis tanah dan metode konservasi yang berbeda-beda telah dilakukan oleh Pusat Penelitian Tanah Bogor untuk periode 1970 sampai 1990. Hasil yang diperoleh menyimpulkan bahwa ada kemungkinan yang amat besar untuk menurunkan aliran permukaan dengan penerapan metode konservasi yang tetap, khususnya untuk lahan kering/tegal dengan permeabilitas yang rendah.

Manajemen pengelolaan air perlu. Tidak hanya untuk air permukaan, juga termasuk air tanah. Menjaga kelestarian air tanah, maka perlu dijaga keseimbangan antara pengisian dan pengambilannya.

Pengisian air tanah secara buatan. Walaupun telah dibangun bendungan pada suatu sungai, sebagian dari air yang mengalir pada musim hujan (khususnya pada tahun basah), masih terbuang keluar waduk. Kelebihan air ini menjadi mubazir dan hanya dapat digunakan melalui konservasi dengan menyimpannya dalam tanah melalui pengisian buatan, dan menggunakannya pada tahun-tahun kering. Simpanan air tanah ini merupakan sumber air yang dapat diandalkan untuk menambah air pada permukaan yang ada. Kemampuan tanah untuk menyimpan air tergantung dari volume pori-pori tanah dan tinggi muka air tanah.

Dalam manajemen pengelolaan air termasuk juga pemakaian air. Konservasi air dapat dilakukan dengan melaksanakan efisiensi pemakaian/penggunaannya. Efisiensi pemakaian air atau penggunaan (EPA) dinyatakan dalam banyaknya hasil yang diperoleh persatuan unit air yang digunakan. Hasil dalam hal ini dapat dinyatakan dalam kilogram bahan kering per liter air atau ton bahan kering per 
meter kubik. Pemakaian air dapat dihitung pada beberapa tingkat berdasarkan sistem atau jaringan yang digunakan untuk mendistribusikan air dari sumber sampai ke pengguna. Untuk sistem irigasi sawah atau ladang, pintu tersier, pintu sekunder, dan pada pintu primer.

Manajeman pengelolaan air bertujuan untuk meningkatkan dan mempertahankan kualitas. Air di dalam sangat jarang ditemukan dalam keadaan murni. Sekalipun air hujan, meskipun awalnya murni, telah mengalami reaksi dengan gas-gas di udara dalam perjalanannya turun ke bumi dan selanjutnya terkontaminasi selama mengalir di atas permukaan bumi dan dalam tanah.

Kualitas air dianggap penting, namun dalam bidang pertanian, hal yang lebih penting adalah ketersediaan air. Terutama air untuk irigasi. Untuk keberhasilan suatu pertanian beririgasi, kualitas air merupakan faktor yang sama pentingnya dengan kualitas tanah/kualitas air pada sunga-sungai di daerah basah pada umumnya memenuhi syarat untuk irigasi, kecuali sungai-sungai yang telah melewati daerah industri, dimana sering telah terpolusi oleh limbah industri yang dapat menghambat pertumbuhan tanaman. Pemberian air irigasi dengan kualitas yang bagus dapat memperbaiki tanah, karena kandungan kalsium dalam air dan keuntungan dari proses pencucian kelebihan garam dari tanah. Secara umum, untuk keperluan air irigasi atau pertanian, faktor yang menentukan kesesuaian air ada empat, yaitu (1) konsentrasi total garam dan terlarut, (2) jumlah sodium relatif terhadap kation lain, (3) konsentarsi boron dan unsur-unsur yang beracun lainnya, dan (4) konsentrasi bikarbonat.

Ketersedian air baik air permukaan akan mengalir lewat alur sungai mulai dari hulu sampai hilir. Daerah sekitar sungai sering dikenal sebagai Daerah Aliran Sungai (DAS). Konsep daerah aliran sungai atau yang sering disingkat dengan DAS merupakan dasar dari semua perencanaan hidrologi. Mengingat DAS yang besar pada dasarnya tersusun dari DAS-DAS kecil, dan DAS kecil ini juga tersusun dari DAS-DAS yang lebih kecil lagi. Secara umum DAS dapat didefinisikan sebagai suatu wilayah, yang dibatasi oleh batas alam, seperti punggung bukit-bukit atau gunung, maupun batas buatan, seperti jalan atau tanggul, dimana air hujan yang turun di wilayah tersebut memberi kontribusi 
aliran ke titik kontrol (outlet). Menurut kamus Webster, DAS adalah suatu daerah yang dibatasi oleh pemisah topografi, yang menerima hujan, menampung, menyimpan dan mengalirkan ke sungai dan seterusnya, ke danau atau ke laut. Apapun definisi yang kita anut, DAS merupakan suatu ekosistem dimana di dalamnya terjadi suatu proses interaksi antara faktor-faktor biotik, nonbiotik dan manusia. Sebagai suatu ekosistem, maka setiap ada masukan (input) ke dalamnya, proses yang terjadi dan berlangsung didalamnya dapat dievaluasi berdasarkan keluaran (output) dari ekosistem tersebut. Komponen masukan dalam ekosistem DAS adalah curah hujan, sedangkan keluaran terdiri dari debit air dan muatan sedimen. Komponen-komponen DAS yang berupa vegetasi, tanah dan saluran/sungai dalam hal ini bertindak sebagai prosessor.

Dalam melaksanakan pembangunan ekonomi khususnya pembangunan pertanian, air merupakan unsur utama. Masalah utama yang sulit dalam pengelolaan sumber daya air adalah penentuan potensi sumber daya air, untuk proyek pertanian. Dengan penelitian ini, maka diharapkan dapat mengidentifikasi segala masalah yang berhubungan dengan Potensi Sumber Daya Air.

\section{METODOLOGI PENELITIAN}

Adapun metode yang digunakan di dalam penelitian ini adalah deskriptif analisis. Lokasi penelitian adalah Bendungan "Tiwungaja". Teknik analisa data adalah dengan cara: Penentuan lokasi untuk perluasan sawah baru. Lokasi potensial untuk irigasi Tiwungaja menggunakan analisis SWOT. Metode SWOT Analisis dalam penelitian ini terdiri dari analisis eksternal dan analisis internal. 


\begin{tabular}{|c|c|c|}
\hline ANALISIS & $\begin{array}{c}\text { STRENGTHS }(\mathrm{S}) \\
\text { Tentukan } 14 \text { kekuatan } \\
\text { irigasi bendungan } \\
\text { Tiwungaja. }\end{array}$ & $\begin{array}{l}\text { WEAKNESS }(\mathrm{W}) \\
\text { Tentukan } 3 \text { kelemahan irigasi } \\
\text { bendungan Tiwungaja. }\end{array}$ \\
\hline OPPORTUNITIES & LOKASI S-O & LOKAs \\
\hline $\begin{array}{l}\text { (O) } \\
\text { Tentukan } 4 \text { peluang } \\
\text { irigasi bendungan } \\
\text { Tiwungaja. }\end{array}$ & $\begin{array}{l}\text { Tentukan lokasi untuk } \\
\text { pengelolaan } \\
\text { dengan menggunakan } \\
\text { kekuatan } \\
\text { memanfaatkan peluang } \\
\text { dari irigasi Tiwungaja } \\
\text { untuk perluasan areal } \\
\text { sawah. }\end{array}$ & $\begin{array}{lrr}\text { Tentukan } & \text { lokasi } & \text { untuk } \\
\text { pengelolaan } & \text { irigasi dengan } \\
\text { menggunakan } & \text { kekuatan } \\
\text { dengan } & \text { meminimalkan } \\
\text { kelemahan } & \text { irigasi irigasi } \\
\text { Tiwungaja } & \text { perluasan areal } \\
\text { sawah. } & & \end{array}$ \\
\hline TREATHS (T) & LOKASI S-T & LOKASI W-T \\
\hline $\begin{array}{lr}\text { Tentukan } & 4 \\
\text { ancaman } & \text { irigasi } \\
\text { bendungan } & \\
\text { Tiwungaja. } & \end{array}$ & $\begin{array}{l}\text { Tentukan lokasi untuk } \\
\text { pengelolaan } \\
\text { dengan menggunakan } \\
\text { kekuatan } \\
\text { menghindari ancaman } \\
\text { dari irigasi Tiwungaja } \\
\text { untuk perluasan areal } \\
\text { sawah. }\end{array}$ & $\begin{array}{l}\text { Tentukan lokasi untuk } \\
\text { pengelolaan irigasi dengan } \\
\text { miminimalkan kelemahan } \\
\text { dan menghindari ancaman } \\
\text { dari irigasi Tiwungaja untuk } \\
\text { perluasan areal sawah. }\end{array}$ \\
\hline
\end{tabular}

Membuat Desain Dasar saluran irigasi bendungan Tiwungaja adalah sebagai berikut:

1) Desain dasar manajemen air yang meliputi: a. Pengelolaan air, b. Pengelolaan vegetasi, c. Pengelolaan bangunan fisik, d. Pengelolaan Alur sungai, dan e. Pengelolaan organisasi dan kelembagaan.

2) Petak Teknik yang meliputi: a. Peta Wilayah, b. Peta DAS, c. Peta Pengairan, d. Peta Pengembangan areal sawah, e. Peta tata guna lahan, dan f. Peta tata ruang DAS.

3) Gambar Teknik meliputi: a. Gambar teknik bangunan fisik dan b. Rencana Anggaran Biaya bangunan fisik.

\section{HASIL DAN PEMBAHASAN}

\section{ANALISIS SWOT}

\section{Rekapitulasi Hasil Perhitungan SWOT}

Berdasarkan hasil perhitungan yang telah dilakukan melalui analisis SWOT, maka didapatkan nilai akhir dari faktor-faktor internal yaitu kekuatan dan 
kelemahan, serta faktor-faktor eksternal yaitu peluang dan ancaman (Wulandari, 2009), dengan perolehan sebagai berikut:

Tabel 1. Rekapitulasi perhitungan nilai kekuatan, kelemahan, peluang dan ancaman

\begin{tabular}{ccc}
\hline No & Uraian & Nilai \\
\hline 1 & Faktor Internal & \\
& Kekuatan & 2,093485 \\
& Kelemahan & 1,331916 \\
\hline 2 & Faktor Eksternal & \\
& Peluang & 1,904834 \\
& Ancaman & 1,906932 \\
\hline
\end{tabular}

Sumber: Data Primer diolah, 2018

Berdasarkan hasil rekapitulasi pada tabel diatas, maka strategi keseluruhan dapat diketahui dengan menggunakan peluang sebaik-baiknya, mencoba meminimalisir kelemahan, menggunakan tingkat kekuatan sebagai modal utama dasar operasi serta menekan ancaman yang ada pada perusahaan. Matriks SWOT proses pengambilan keputusan strategis selalu berkaitan dengan pengembangan misi, tujuan, strategi, dan kebijakan Desa Sobo I. Dengan demikian, perencanaan strategis (strategic planner) harus menganalisis faktor-faktor strategis Desa (kekuatan, kelemahan, peluang, dan ancaman). Setelah menentukan faktor internal yaitu kekuatan dan kelemahan dan faktor eksternal peluang dan ancaman, kemudian menentukan strategi-strategi untuk pembangunan irigasi Tiwungaja yang dianalisis menggunakan matriks SWOT.

Hasil dari matriks SWOT tersebut, secara ringkas dapat dilihat pada Tabel 2 berikut.

Tabel 2. Pembobotan dari hasil kuesioner SWOT

\begin{tabular}{ccc}
\hline EFAS & $\mathrm{S}=2,054532$ & $\mathrm{~W}=1,343968$ \\
\hline $\mathrm{O}=1,947398$ & $\mathrm{SO}=4,001930$ & $\mathrm{WO}=3,291366$ \\
\hline $\mathrm{T}=1,938341$ & $\mathrm{ST}=3,992873$ & $\mathrm{WT}=3,282309$ \\
\hline
\end{tabular}

Sumber: Data primer diolah, 2018

Berdasarkan tabel diatas, maka disusun prioritas strategi berdasarkan kombinasi strategi yang memiliki nilai paling tinggi sampai paling rendah, sebagaimana yang terdapat pada Tabel 3 berikut: 
Tabel 3. Urutan alternatif strategi SWOT

\begin{tabular}{clc}
\hline PRIORITAS & \multicolumn{1}{c}{ STRATEGI } & BOBOT NILAI \\
\hline 1 & Strength - Opportunity (SO) & 4,001930 \\
\hline 2 & Strength - Threat (ST) & 3,992873 \\
\hline 3 & Weakness - Opportunity (WO) & 3,291366 \\
\hline 4 & Weakness - Threat (WT) & 3,282309
\end{tabular}

Sumber: Data primer diolah, 2018

Berdasarkan tabel diatas, urutan alternatif strategi SWOT, bahwa StrengthOpportunity (SO) menghasilkan bobot tertinggi, dimana sebagai strategi yang memanfaatkan seluruh kekuatan untuk merebut dan memanfaatkan peluang yang sebesar-besarnya. Strategi Strength - Opportunity (SO) berdasarkan matriks SWOT pada tabel diatas, memiliki beberapa strategi kebijakan sebagai berikut: Tentukan lokasi untuk pengelolaan irigasi dengan menggunakan kekuatan untuk memanfaatkan peluang dari irigasi Tiwungaja untuk perluasan areal sawah. Sumber mata air irigasi di hulu cukup untuk mengairi sawah, debit air irigasi yang tersedia cukup untuk areal sawah, debit air puncak musim hujan cukup untuk areal sawah, debit air puncak saat banjir cukup untuk areal sawah, debit air yang tersedia digunakan untuk pertanian, lokasi bendungan dan calon lahan pertanian pernah disurvey untuk dibangun.

\section{Analisis Deskripsi Wilayah Irigasi Tiwungaja}

Desa Sobo terletak di bagian utara Kecamatan Golewa Barat, mempunyai 4 buah mata air. Desa ini mengalir 3 kali besar yang menjadi hulu sungai Aesesa, yaitu kali Wae Bula, kali Pazo, kali/loko Langa dan kali Wae Aku Ina/Ola Bolo yang mengairi areal sawah di Desa Sobo I seluas 350 hektar.

Kali Wae Bula mengalir di sisi barat Desa Sobo I, dengan Bendungan Tiwu Ngaja dan Bendungan Dorarapu. Bedungan Tiwungaja dengan jaringan irigasi Tiwungaja akan dapat mengairi sawah seluas 99,069 hektar. Namun jaringan irigasi masih belum sesuai dengan standar irigasi yang normal, karena jaringan irigasi dari bendungan adalah saluran irigasi primer, tanpa pintu pengatur air, mulai dari jaringan irigasi primer sampai dengan jaringan irigasi tersier yang masuk ke petak sawah. Panjang jaringan irigasi Tiwungaja masing-masing ruas 
(jarak dalam satuan meter) Tahun 2018, dengan uraian sebagai berikut : Bendungan Tiwungaja (0 $\mathrm{m})$ - Jaringan primer bendungan ke pintu pembuangan banjir (500 m) - Jaringan primer pintu pembuangan banjir - Pintu I (280 m) - Bok Deker dekat sawah Mia Moi ( 41 m) - Bok Deker I - Pintu II (12 m) - Pintu II Bok Deker II (198 m) - Bok Deker II - Pintu III (108 m) - Bok Deker III (28 m) Bok Deker IV - Pintu IV (134 m) - Pintu IV - Bok Deker V (255 m) - Bok Deker V - Bok Deker VI (125 m) - Bok Deker VI - Pintu V (72 m) - Pintu V - Pintu VI (40 m) - Pintu VI - Pintu VII (176 m) - Pintu VII - Bok Deker VII (120 m) - Bok Deker VII - Pintu VIII (120 m) - Pintu VIII - Pintu IX (120 m) - Pintu IX - Pintu X (120 m) - Pintu X - Pintu XI (120 m) - Pintu- XI - Pintu XII (80 m) - Pintu XII - Alo Pazo (265 m). Sehingga total jarak dari bendungan Tiwungaja sepanjang 2.914 meter.

Pintu air untuk saluran primer jaringan irigasi Tiwungaja dan desain pintu air untuk masing-masing ruas jaringan irigasi adalah sebagai berikut : Pintu Air / Nama Pintu Air Saluran Primer Jaringan Irigasi Tiwungaja Masing - masing Ruas Tahun 2018. Uraian terinci sebagai berikut : Bendungan Tiwungaja (0 m) - Pintu pembuangan / Pintu Penutup Saluran Irigasi, Jika Banjir (500 m) - Pintu I (280 m) - Bok Deker I (41 m) - Pintu II (12 M) - Bok Deker II (198 m) - Pintu III (108 m) - Bok Deker IV (28 m) - Pintu IV (134 m) - Bok Deker V (255 m) - Bok Deker VI (125 m) - Pintu V (72 m) - Pintu VI (40 m) - Pintu VII (176 m) - Bok Deker VII (120 m) - Pintu VIII (120 m) - Pintu VIX (120 m) - Pintu X (120 m) - Pintu XI (120 m) - Pintu XII (80 m) - Alo Pazo (265 m).

Luas sawah potensial yang mendapatkan pengairan dari Bendungan Tiwungaja adalah sebagai berikut : 1). Areal sawah Tiwungaja seluas 18,054 ha, 2). Kopo Kolo seluas 63,81 ha dan 3). Sabu Rowa seluas 17,205 ha. Total Luas 99,069 ha. Bendungan Tiwungaja dengan jaringan irigasi Tiwungaja akan dapat mengairi sawah seluas 99,069 hektar. Namun jaringan jalan masih belum sesuai dengan standar jalan yang normal dengan lebar 6 meter, karena jaringan jalan dari bendungan sampai dengan areal sawah belum terhubung, hanya berupa jalan setapak. Jaringan jalan ini akan berfungsi ganda, selain menjadi jalur jalan ekonomi untuk mengangkut hasil pertanian dan jalan inspeksi saluran irigasi, 
P-ISSN 2580 - 7781

E-ISSN $2615-3238$

untuk peningkatan dan perawatan jaringan irigasi. Namun masih ada fungsi lain atas jalan ini, karena akan menjadi jaringan penghubung antar dusun di Desa Sobo I. Jaringan jalan sepanjang jaringan irigasi Tiwungaja menuju areal sawah pada masing-masing ruas jalan adalah sebagai berikut : Pelataran Bendungan $(0 \mathrm{~m})$ Bendungan - Pintu pembuangan banjir (500 m) - Pintu pembuangan banjir - Pintu IV (300 m) - Pintu IV - Pintu VII (668 m) - Pintu VII- Pintu XII (560 m) - Pintu XII - Alo Pazo (265 m). Jalan inspeksi irigasi Tiwungaja sepanjang 2.914 meter.

\section{Rencana Anggaran dan Biaya (RAB)}

Dalam rangka mengefektifkan pemanfaatan air irigasi dari Bendungan Tiwungaja, untuk mengairi sawah seluas 99,069 hektar, yang tersebar di areal sawah Tiwungaja, Kopo Kolo dan Sabu Rowa. Rencana Anggaran dan Biaya (RAB) Jaringan Irigasi Tiwungaja masing-masing Ruas Saluran Irigasi Tahun 2018 adalah sebagai berikut : Rencana anggaran mulai dari Bendungan Tiwungaja sampai dengan Pintu IV telah dilaksanakan, sehingga tidak ada anggaran. Sedangkan dari Pintu IV - Bok Deker V (255 m) anggaran Rp 311.579.400, Ruas Bok Deker V - Bok Deker VI (125 m) anggaran Rp 152.735.000, Ruas Bok Deker VI - Pintu V (72 m) Rp 87.975.360, Ruas Pintu V - Pintu VI (40 m) anggaran Rp 48.875.200, Ruas Pintu VI - Pintu VII (176 m) anggaran Rp 215.050.880. Ruas Pintu VII - Bok Deker VII (120 m ) anggaran Rp 146.625.600. Ruas Bok Deker VII - Pintu VIII (120 m) anggaran Rp 146.625.600. Ruas Pintu VIII - Pintu IX (120 m) anggaran Rp 146.625.600. Ruas Pintu IX - Pintu X (120 m) anggaran Rp 146.625.600. Ruas Pintu X - Pintu XI (120 m) anggaran Rp 146.625.600. Ruas Pintu- XI - Pintu XII (80 m) anggaran Rp 97.750.400. Ruas Pintu XII - Alo Pazo (265 m) anggaran Rp 323.798.200. Total panjang jaringan irigasi sepanjang 1.613 meter dengan anggaran Rp 1.970.892.440.

Rencana biaya pintu air untuk saluran primer jaringan irigasi Tiwungaja dan desain pintu air untuk masing-masing ruas jaringan irigasi adalah sebagai berikut : Pintu Pembuangan Rp 25.000.000, - Pintu Penutup Saluran Irigasi, Jika Banjir Rp 16.000.000, - Pintu I Rp 15.600.000, - Pintu II Rp 16.800.000, - Pintu III Rp 16.800.000, - Pintu IV Rp 16.800.000, - Pintu V Rp 13.440.000, - Pintu IV Rp 13.440.000, - Pintu VII Rp 13.440.000, - Pintu VIII Rp 13.440.000, - Pintu VIX 
Rp 13.440.000, - Pintu X Rp 13.440.000, - Pintu XI Rp 13.440.000, - Pintu XII Rp 13.440.000. Sehingga total seluruh biaya investasi untuk pintu air $\mathrm{Rp}$ 214.520.000. Rencana anggaran dan biaya (RAB) pencetakan sawah siap tanam (pembuatan bedengan sawah siap tanam) sebesar Rp 466.280.000,- dengan luas 99,069 hektar.

Bendungan Tiwungaja dengan jaringan irigasi Tiwungaja akan dapat mengairi sawah seluas 99,069 hektar. Namun jaringan jalan masih belum sesuai dengan standar jalan yang normal dengan lebar 6 meter, karena jaringan jalan dari bendungan sampai dengan areal sawah belum terhubung, hanya berupa jalan setapak. Jaringan jalan ini akan berfungsi ganda, selain menjadi jalur jalan ekonomi untuk mengangkut hasil pertanian dan jalan inspeksi saluran irigasi, untuk peningkatan dan perawatan jaringan irigasi. Namun masih ada fungsi lain atas jalan ini, karena akan menjadi jaringan penghubung antar dusun di Desa Sobo I. Rencana biaya jaringan jalan sepanjang jaringan irigasi Tiwungaja menuju areal sawah pada masing-masing ruas jalan adalah sebagai berikut: Pelataran Bendungan (Parkir) Rp 172.000.000, - Bendungan - Pintu pembuangan banjir Rp 144.000.000, - Pintu pembuangan banjir - Pintu IV (Sawah Yohanes N) Rp 86.400.000, - Pintu IV - Pintu VII Rp 192.384.000, - Pintu VII- Pintu XII (Jalan Boa Tuku - Boa Botu) Rp 161.280.000, - Pintu XII - Alo Pazo (lewat tengah Boa Tuku, Sawah Ema Dara Sego (Sawah Saburowa B) Rp. 76.320.000,. Sehingga total seluruh anggaran ruas jalan sepanjang $2.914 \mathrm{~m}$ adalah sebesar Rp. 832.384.000.

Dalam rangka menunjang jaringan jalan sepanjang jaringan irigasi Tiwungaja menuju areal sawah pada masing-masing ruas jalan, perlu dibangun bok deker/jembatan. Rincian adalah sebagai berikut : Bok Deker I volume $12 \mathrm{~m} 3$ Rp 190.000.000 (dekat sawah Mia Moi), - Bok Deker II $24 \mathrm{~m}^{3}$ Rp 230.000.000 (Dekat sawah Kons Wake), - Bok Deker III $12 \mathrm{~m}^{3} \mathrm{Rp}$ 190.000.000, - Bok Deker IV $24 \mathrm{~m}^{3} \mathrm{Rp} 230.000 .000$ (dekat Pondok Safa Oje), - Bok Deker V Rp 230.000.000 (Alo Ema Eno) $24 \mathrm{~m}^{3}$, - Bok Deker VI (Sawah Ine Nango Meo) 24 $\mathrm{m}^{3}$ Rp 230.000.000, - Bok Deker VII (Alo Belakang Boa Botu) $36 \mathrm{~m}^{3} \mathrm{Rp}$ 
P-ISSN 2580 - 7781

E-ISSN $2615-3238$

280.000.000. Total seluruh bok deker sebanyak 7 unit, volume $156 \mathrm{~m}^{3}$ dengan anggaran $\mathrm{Rp}$ 1.580.000.000.

Rekapitulasi Rencana Anggaran dan Biaya (RAB) jaringan irigasi, pintu air, pencetakan sawah, jalan dan bok deker adalah sebagai berikut : Jaringan irigasi dengan anggaran Rp 1.970.892.440,- untuk pintu air Rp 214.520.000,- pencetakan sawah $\mathrm{Rp}$ 466.280.000,- jaringan jalan $\mathrm{Rp}$ 832.384.000,- bok Deker $\mathrm{Rp}$ 1.580.000.000,- Sehingga total anggaran Rp 5.064.076.440,--

\section{KESIMPULAN}

Panjang jalan inspeksi saluran irigasi primer $2.914 \mathrm{~m}$, dengan bok deker 156 $\mathrm{m}^{3}$. Gambar dan rencana anggaran biaya (RAB) Jalan Inspeksi Saluran Irigasi dengan Anggaran Rp 2.412.384.000,-. Panjang saluran irigasi primer $2.914 \mathrm{~m}$. Gambar dan rencana anggaran biaya (RAB) saluran irigasi primer dengan Anggaran Rp 1.970.892.440,-. Pintu air saluran sekunder sebanyak 12 pintu air, Gambar dan rencana biaya (RAB) pintu air saluran sekunder dengan anggaran Rp 214.520.000,-. Luas areal sawah baru 17,205 Ha. Gambar dan rencana anggaran biaya (RAB) pencetakan sawah baru Rp 466.280.000,-. Hasil yang dicapai dari kegiatan penelitian ini adalah Perluasan Areal Sawah, Seluas 99,069 Ha di Irigasi Tiwungaja.

\section{DAFTAR PUSTAKA}

Asdak Chay, 2001, Hodrologi dan Pengelolaan Daerah Aliran Sungai, Gadjah Mada University Press, Yogyakarta.

Arsyad S, 1989, Konservasi Tanah dan Air, Institut Pertanian Bogor Press, Bogor.

Bregmann, Helllmuth, and Jean-March Bussard, 1976, Guide to the Economic Evaluation of Irigation Projects, Paris, Organisation for Economic Cooperation and Development (OECD).

Carruthers, Ian, and Colin Clark, 1981, The Economic of Irigation, Liverpool, Liverpool University Press

Gittinger Pruce J, 1986, Analisa Ekonomi Proyek - Proyek Pertanian, Edisi Kedua, Penerbit Universitas Indonesia (UI-Press), Jakarta. 379 halaman.

Gemmell Norman, 1994, Ilmu Ekonomi Pembangunan, Beberapa Survey, Penerbit PT Pustaka LP3ES Indonesia, Jakartam 552 halaman. 
P-ISSN 2580 - 7781

E-ISSN $2615-3238$

Nangameka Yohanes, 2009, Kajian Pengelolaan Potensi Sumber Daya Air, Daerah Aliran Sungai (Das), Untuk Penentuan Proyek Pertanian, Di Kabupaten Ngada, Nusa Tenggara Timur, Situbondo 52 Halaman.

Nangameka, Yohanes., 2016, Kajian Pemanfaatan Sisa Air Irigasi Pada Musim Kemarau Untuk Komoditi Palawija Di Daerah Aliran Sungai (DAS) Kabupaten Ngada Nusa Tenggara Timur, Situbondo, 49. Halaman.

Suripin, 2001, Pelestarian Sumber Daya Tanah Dan Air, Penerbit Andi Yogyakarta.

Prawirowardoyo, 1996, Meteorologi, Penerbit ITB Bandung. 